\title{
Caring for the Caregivers: Mental and Spiritual Support for Healthcare Teams During the COVID-19 Pandemic and Beyond
}

\author{
Gilad E. Amiel $^{1} \cdot$ Nirit Ulitzur ${ }^{1}$ \\ Published online: 15 September 2020 \\ (C) American Association for Cancer Education 2020
}

The unique challenges that the COVID-19 pandemic has put upon us are more pronounced when dealing with cancer patients. Healthcare teams are adjusting to an ever-changing environment with an elusive disease that requires adaptation to new practices. Since much of the effort is directed toward Corona-dedicated departments, other teams are depleted, while required to maintain the same level of service. When dealing with cancer patients, things are even more complex: among those who do come to get treated, many are immunecompromised and are at a higher risk of complications upon contracting the virus. Others are reluctant to seek medical care in hospitals since they are perceived as "risky" places to contract the disease. We are starting to see patients that postponed seeking medical care in previous months and currently presenting with malignancies at later stages of their disease [1]. All this puts a huge burden on healthcare providers in general and those who treat cancer patients in particular. Positive professional quality of life leads to compassion satisfaction and better patient care. However, with the increased burden the tables turn.

\section{Identifying the Problem}

Even before the start of the COVID-19 pandemic, burnout (BO) among caregivers in general, and physicians in particular, was widespread. About $30 \%$ of all American surgeons were reported to suffer from $\mathrm{BO}[2,3]$. BO is caused by exhaustion, frustration, anger, and depression. This leads to negative professional quality of life and two possible detrimental effects: compassion fatigue (CF) and secondary

Gilad E. Amiel

G_AMIEL@rambam.health.gov.il

1 Department of Urology and the Service of Spiritual Support, RAMBAM Healthcare Campus, Haifa, Israel traumatic stress (STS). CF is a deep sense of emotional exhaustion that healthcare providers can experience while helping others in distress. Interestingly, CF has been studied widely among nurses and mental healthcare professionals, but only recently has been examined among physicians and surgeons [3]. STS is a negative feeling driven by fear and work-related trauma [4]. Therefore, BO not only affects the caregiver's quality of life and health, but also is associated with an increase in medical errors and worse patient outcomes. Additionally, it is well established that sleep deprivation and a critical lack of psychosocial support may aggravate such symptoms [5].

\section{Finding a Solution}

With a few exceptions, hospitals in general are not designed or adapted to provide continuous emotional support to their staff. This was clearly reflected in a recent Israeli National Health Ministry Burnout Report of 40,000 healthcare employees [6]. There is no evidence to support that the situation is much better in other countries around the globe. In many places, there is a service that a healthcare provider can approach when feeling in distress, but it seems that these systems are profoundly underutilized. The detrimental consequences are burnout and compassion fatigue. These lead to reduced functionality and motivation, errors and accidents, increase in sick days and leaves, and more. The importance of looking after doctors' mental well-being during the COVID-19 pandemic has been raised recently $[5,7]$. However, the solutions offered were in the realm of self-help and not proactive institutionally organized systems of support [8].

Beneficial interventions addressing CF have been published in the past [9-12]. Several studies described workshops for residents incorporating meditation and self-care as part of the daily routine. There is no evaluation of long-term follow- 
up of these interventions and their positive effect on the physicians' well-being and patients' safety.

We recently incorporated a pilot workshop at our institution that aimed to support the physicians, residents, and staff alike, to help them maintain their perspective and sense of balance. We developed a basic resilience program that was composed of three weekly sessions. The program was designed to help the surgeons understand $\mathrm{CF}$, recognize the physical, mental, and emotional effects of stress, and adopt resilience strategies based on spiritual care tools (deep listening, non-judgmental peer support, conscious breathing, and connecting to personal resilience resources). The vast majority $(n=20 ; 94 \%)$ of all surgeons who participated in the workshop acknowledged the importance of receiving the provided support and expressed interest in additional sessions. Interestingly, the residents that took part in the program $(n=$ 8) reported a long-lasting positive effect 3 months after the conclusion of the workshop.

This is only one example of a variety of initiatives that hospitals should take to proactively support healthcare teams in these challenging times. Although an emphasis should be made on those who are staffing departments serving COVID19 patients, it is in the interest of all healthcare systems to support teams treating oncologic patients and other practices [13]. They should continuously offer interventions to promote healthcare teams' well-being. This will also no doubt, benefit our patients.

\section{References}

1. Dinmohamed AG, Visser O, Verhoeven RHA, Louwman MWJ, Nederveen FH, Willems SM et al (2020) Fewer cancer diagnoses during the COVID-19 epidemic in the Netherlands. Lanct Oncol 21:750-751

2. Shanafelt TD, Balch CM, Bechamps GJ, Russell T, Dyrbye L, Satele D, Collicott P, Novotny PJ, Sloan J, Freischlag JA (2009)
Burnout and career satisfaction among American surgeons. Ann Surg 250(3):463-471

3. Seemann NM, Karanicolas PJ, Guttman MP, Nathens AB, Tien HC, Ellis J (2019) Compassion fatigue in surgical trainees. J Surg Educ 76(5):1211-1222

4. Stamm BH (2010) The concise ProQOL manual, 2nd edn. ProQOL.org, Pocatello

5. Sultana A, Sharma R, MDM H, Bhattacharya S, Purohit N (2020) Burnout among healthcare providers during COVID-19 pandemic: challenges and evidence-based interventions. RePEc:osf:socarx: 4hxga. Center for Open Science. https://doi.org/10.31219/osf.io/ 4hxga

6. Burnout in the health care system - Health Ministry Report. 2018 (in Hebrew). https://www.health.gov.il/Subjects/ HRinHealthSystem/PreventingBurnoutProgram/Pages/survey burnout_results2018.aspx. Accessed 10 Jan 2018

7. Teoh K, Kinman, G (2020) Looking after doctors' mental wellbeing during the covid-19 pandemic. BMJ Opinion https:// blogs.bmj.com/bmj/2020/03/26/looking-after-doctors-mentalwellbeing-during-the-covid-19-pandemic/. Accessed 04 July 2020

8. Adams JG, Walls RM (2020) Supporting the health care workforce during the COVID-19 global epidemic. JAMA 323(15):1439-1440

9. Sanchez-Reilly S, Morrison LJ, Carey E, Bernacki R, O'Neill L, Kapo J, Periyakoil VS, Thomas J (2013) Caring for oneself to care for others: physicians and their self- care. J Support Oncol 11(2): $75-81$

10. Tucker T, Bouvette M, Daly S, Grassau P (2017) Finding the sweet spot: developing, implementing and evaluating a burnout and compassion fatigue intervention for third year medical trainees. Eval Program Plan 65:106-112

11. Salles A, Liebert CA, Esquivel M, Henry R, Greco RS, Mueller C (2017) Perceived value of a program to promote surgical resident well-being. J Sur Educ 74(6):921-927

12. Kannai R, Biderman A (2019) Methods for burnout prevention and their implementation in the course for family medicine residents in Ben-gurion University of The Negev. Harefuah 158(10):664-668 [Article in Hebrew]

13. van de Haar J, Hoes LR, Coles CE, Seamon K, Fröhling S, Jäger D (2020) Caring for patients with cancer in the COVID-19 era. Nat Med 26:665-671

Publisher's Note Springer Nature remains neutral with regard to jurisdictional claims in published maps and institutional affiliations. 